\title{
CALENDARI I MODERNITAT *
}

Crisi del calendari tradicional i dificultats en la reconstrucció d'un calendari significatiu modern

\author{
Salvador Cardús i Ros \\ (Universitat Autònoma de Barcelona)
}

\section{Crisi del calendari tradicional com a cosmos sagrat}

Històricament, el procés de crisi del calendari tradicional es fa palès en una progressiva falta de coherència entre aquest $-\mathrm{i}$ el cosmos sagrat que era definit per ell- $\mathrm{i}$ les jerarquies de significat definides per la modernitat.

És a dir, que el calendari tradicional fonamentat en les necessitats dels ritmes de producció agrària $i$ els estacionals va perdent progressivament la seva rellevància significativa a mesura que les exigències quotidianes en procés de modernització es separen d'aquestes exigències temporals tradicionals. L'ordenament temporal significatiu construit en el cosmos sagtat tradicional, doncs, topatà frontalment amb les noves experiències quotidianes imposades per la producció tecnològica i industrial i per les seves conseqüùncies, la més notable de les quals serà la del transvasament de població del camp a la ciutat, o procés d'urbanització. És a partir d'aquests canvis en l'experiència de Ia vida quotidiana com es comença a transformar el calendari, amb pèrdues de rellevància d'algunes celebracions, potenciació dels nous ritmes laborals, aparició de nous cicles festius... No es tracta, però, d'un senzill canvi de calendaris amb estructures signifí-

* Aquest articie és una versió adaptada d'un dels capíols de la tesi de doctorat L'estructuració del temps a la societat moderna i la seva representació en el calendari, $\mathrm{UAB}, 1981$. 
catives diferents. El calendari modern es va construint a poc a poc, amb alts i baixos. La cristianització del calendari pagà dels romans també fou fruit d'un procés lent, només possible quart el cristianisme s'hagué convertit en la religió dels emperadors. I encara, la tasca de cristianització del calendari no anava aparellada a canvis radicals en els estils de vida. En realitat es tractava de recórrer a les «mutacions»: la purificació dels Lupercalia es transformaria en la Putificació de la Verge; els Ambarualia (lustració dels camps) en processons rogatives... (C. J. Bleeker, 1969 pp. $474 \mathrm{i}$ ss., I vol.). Els historiadors del període insisteixen en aquestes transformacions - no es tracta pas, doncs, de "supervivències»- que l'Església aplicà per tal d'ofegar les pràctiques paganes, i desvirtuar les creences, assimilant-les eila mateixa, o bé forçada pel poble que conscientment 0 inconscientment les hi assimilava. (Caro Baroja, 1979, p. 81.)

Però aquestes transformacions que foren lentes, s'aplicaren sobre una estructura temporal ja establerta. Hi havia construcció i canvi de significats, però en molt poca mesura, d'estructures temporals. Les festes de maig, per exemple (Caro Baroja, 1979) eren transformades: les «mayas» paganes en festes en honor de la Verge; les festes entorn de l'arbre, en festes de la Creu; etc..., petò es mantenia l'estructura festiva. Els límits d'aquesta tasca de cristianització dels costums els assenyala J. Danielou (1963, pp. 362 i ss.): «només algunes ànimes d'èlite són capaces de prendre consciència de les implicacions pràctiques que es deduïen del nou ideal religiós que acabaven d'entreveure o d'adoptar». I aquestes èlites hi podien accedir per la conversió, que suposa una prèvia desestructuració del coneixement, també del temporal. Però la conversió és un procés d'èlite, i la cristianització a la que s'havien abocat els primers cristians s'havia de valer d'altres recursos més populars.

El cas de les variacions en el calendari modern, s'agreugen perquè no es tracta simplement d'un reajustament en les jerarquies de significat, sinó d'un canvi en la mateixa estructura de l'experiència temporal. Les «vacillacions» de què parlàvem al principi, $i$ que es produeixen en la definició o construcció d'aquest calendari modern, no són noves en la història del calendari. Tanmateix, el que potser és nou, és el fet que les «vacillacions» siguin precisament constitutives del calendari modern, a causa dels processos de pluralisme i privatització que comporta la modernització de la societat, com veurem ata.

Estem convençuts que aquesta crisi calendària coincideix en general amb la crisi de les formes tradicionals de religiositat definides conjuntament amb el calendari; tan íntimament ligades les unes i l'altre per un mateix cosmos sagrat tradicional.

La quitestió problemàtica, però, està en el fet que la pèrdua de plausi- 
bilitat d'aquesta articulació de la jetarquia interna de significats de la visió de món en les societats tradicionals no va acompanyada únicament per una nova articulació, ara moderna, sinó que alhora es produeixen uns processos socials que transformen en bona part eis mecanismes $i$ per tant el funcionament dels sistemes de donació de significats últims, i posen en qüestió l'abast globalitzador dels universos simbòlics de significació.

En definitiva, els processos de segmentació institucional i la consegüent especialització imposada pel sistema de producció industrial, i la parcellació d'àrees de significat autònomes que aquest procés implica, donen lloc a una situació de pluralisme normatiu i de significats, això és, a un pluralisme cultural, que en bona part és el responsable de la pèrdua de les pretensions de globalitat dels cosmos sagrats tradicionals. ${ }^{.}$

A efectes del calendari, el pluralisme normatiu segons cada àrea institucional especialitzada $i$ autònoma -món laboral (ell mateix subdividit), món escolar, món administratiı, món cometcial, etc.- donarà lloc a l'apatició de calendatis especialitzats, amb els seus horatis, ordenaments festius..., no només difetents entre ells, sinó fins i tot contradictoris. Si en el terreny dels rols que es defineixen en cada àrea institucional es pot parlar de «conflicte de rols» conseqüència de l'especialització i segmentació institucional en la societat moderna, també en el terreny dels calendatis o ordenament temporal social, podem parlar de conflicte de calendaris. Les dificultats individuals, familiars i de grup per establir acords d'horaris és cada vegada més accentuada, així com també per establir acords festius i de vacances.

L'interessant d'aquests «conflictes» és que acaben apareixent com a necessaris $i$ constitutius de la mateixa racionalitat moderna.

Només per posar un exemple, cada vegada es fa més evident, segons aquesta tacionalitat, que els periodes de vacances d'estiu necessiten diversificar-se si no durant tot l'any, sí més no durant els mesos de juny a setembre. Els arguments són les dificultats en la capacitat hotelera del país, la falta de places els mesos punta de turisme estranger, la desocupació de les places durant la resta d'any, etc. Novament hi ha una qüestió no de conflicte de significats, sinó en el mateix ritme temporal. Les conse-

1. Aquesta globalitat significativa en la societat tradicional, queda exposada en L. Febvre (1942): «Al segle xvi tots els actes, tots els dies estan com saturats de religió (...). En una paraula, tot sembla dependre de l'Esglesia, encara. Fins i tot el temps (...) els campanars de les esglésies, anunciant del matí al vespre, a hores conegudes, la successió de les pregàries $i$ dels oficis. Ảdhuc el calendari, que hom fa parlar en cristià: hi ha ben bé cent dies dels 365 que són anomenats pel nom d'un Sant i no per un dia abstracte del mes...) (p. 315). És més, encara. Tal com điu Van der Leeuw (1948), cada festa del cícle equival a un microcosmos del conjunt del temps (p. 383). 
qüències seran positives per a la racionalitat econòmica, però a nivell significatiu es produirà, presumiblement, una accentuació del caràcter privat $i$ individualitzat de les vacances, una nova desestructuració del ritme global anual per donar pas a les experiències temporals aillades, puntuals, sense relació amb el conjunt.

Però el conflicte de calendaris encata s'agreuja per l'existència d'aquesta diversitat de propostes - $-\mathrm{i}$ de normes- temporals segons la institució. No ha de sorprendre, doncs, que en el món eclestàstic, uns laics demanin celebracions de la penitència a l'inici de curs, i no per l'Advent o la Quaresma. O que llegim en un catàleg comercial una salutació que s'inicia amb un: «Feliç tardor nova!», afirmant seguidament amb convicció que l'any humà no comença el gener sinó el setembre. I en dóna la raó: «¿Saps per què? Perquè són les vacances les que realment assenyalen les etapes.» I com sempre, el predomini de la racionalitat utilitària moderna. «El gener és tradicional i sentimental, petò el setembre és efectius.»

Vet aquí els conflictes entre els calendaris litúrgic, comercial, civil, festiu, vacacional i laboral, escolar...

La conseqüència del pluralisme normatiz respecte cada àrea institucional queda clarament expressada. Però en canvi encara no hem parlat prou de la pluralitat de significats, que és on més clar es veu la dificultat de mantenir cosmos sagrats globalitzants.

Fent un símil amb el procés seguit pels fenòmens religiosos dels quals el calendari tradicional en formaria patt, diriem que s'ha produit un procés de rutinització del calendari festiu, de la mateixa festa. El calendari festiu, expressió temporal d'una determinada visió del món, esdevé progressivament «pràctica» $\mathrm{i}$ «creença», termes amb els que T. Luckmann (1967, p. 96) caracteritza també la forma actual de religiositat tradicional.

Es a dir, que queda segregat a unes àrees específques de manera que la seva «jurisdicció» significativa, abans englobadora, ara es redueix, $i$ en part es distribueix entre les diferents àrees institucionals. ${ }^{2}$

EIs calendaris especiffics de cada àrea institucional tindran únicament uns significats pragmàtics, que és un dels primers nivells de complexitat significativa que defineixen Berger i Luckmann (1966) en els cosmos sagrats.

2. Coincidiria amb aquesta perspectiva l'afitmació de B. Besret (1971) al referirse a l'evolució de la festa del diumenge ctistià: «El cristià, que es definia abans com "1'home de la festa", ha esdevingut un "practicant" (p. 200). Les tecents reformes Litúrgiques, per l'autor, no han suscitat cap renovellament de la festa. Han passat del to misteriós i incomprensible anterior a una pobresa, a un tacionalisme larvat, «que explica, sense per aixd justiffcar-Ies, les reaccions a vegades violentes dels cristians nostàlgics.... (p. 157). 
La festa, definida per aquest calendari tradicional que englobava els diferents aspectes de la vida social, es rutinitza doncs, i perd el seu caràcter sagrat i esdevé, com dèiem, senzillament "pràctica» amb uns significats reduitts $i$ particulars $i$ per tant precaris en el seu manteniment $i$ condemnats a diversificar-se segons els defineixin els diferents grups $i$ individus. Per tant, la festa, i el calendari tradicional que la definia i situava en un continuum ben travat, deixeñ de tenir una significació global i adquireixen un significat parcial.

Els exemples que hem anat posant ens mostren també aquesta parcialitat en els significats. Parcialitat en un doble sentit: no afecten tota l'àrea d'experiència temporal $\mathrm{i}$ no afecten al conjunt dels individus. En el primer cas, volem dir que no hi ha cap línia «argumental» que estructuri o relacioni els diferents significats tempotals: festes, vacances, caps de setmana... És l'absència de l'ordre passional d'en Caro Baroja: a un cap de setmana en succeeix un altre sense cap relació significativa que els pugui englobar. Petò a més, $i$ aquí hi ha l'altra dimensió de parcialitat -i seguint amb l'exemple dels caps de setmana - vet aquí que es produeix dispersió social i no augment de relacions significatives, que hi ha múltiples formes de concebre $i$ donar sentit al cap de setmana, bi ha pluralitat de significacions no compartides, i doncs parcials. I no en parlem, si ens refetim a festes específiques, on la diversitat de sentits pot augmentar segons el gust individual de cadascú.

Pel que fa a l'esfera religiosa, el procés acaba també destinant als afers religiosos, una dedicació parcial, i també, igual que en el calendari, es debilita la seva posició de supetioritat significativa en el sistema de rellevància subjectitu.

Aquesta pèrdua de rellevancia significativa del calendari tradicional s'agreuja també per la introducció d'elements de racionalitat econòmica, que debiliten encara més la coherència d'aquest calendari. Els elements de racionalitat - tecnològica i consumista, és clar-- serveixen per argüir suptessions festives $i$ fins $i$ tot, per sollicitar un calendari nou, en el qual els períodes de producció no es veurien «importunats» per talls que trenquen la setmana laboral. En la premsa hem llegit, respecte a una possible reforma del calendari que es tracta d'un «suggeriment raonable, fet amb la intenció de facilitar la dinamica de la societat moderna, principalment l'economia, la tasca escolar i l'esplai humày - eis subratllats són nostres(Avui, 1-XII-1979). La proposta encara és més suggerent, venint cơn ve del pare caputxí Jordi Illimona. ${ }^{3}$

3. L'article citat d'en J. Llimona (1979) és un comentari al calendari de festes i laboral de la Generalitat de Catalunya per a 1980. Pet exemple, en Llimona, entre 
Heus aquí, doncs, d'una manera explícita, exposada la necessitat d'introduir la racionalitat modernitzant, de caràcter especialment econòmic, ja que, de fet, la institució escolar i sobretot l'oci formen part d'aquesta mateixa racionalitat més que no pas s'hi oposen o la complementen.

Comprenem la dificultat creixent de mantenir el valor anbistòric necessa. ri del calendari tradicional pels especialistes encarregats de legitimar-lo. Tot el contrati, actualment, els elements de racionalitat, el caràcter historicista de les anàlisis, la valoració positiva del canvi en si mateix com a índex -illusori- de progrés..., tot conflueix a fer notar precisament el caràcter relatitu del calendari, en les seves inexactituds històriques - des del zaixement de Crist, que no havia estat un 25 de desembre, fins a les inexactituds astronòmiques, etc. ${ }^{4}$

La crisi del calendari tradicional en la societat moderna, i la seva anàlisi, ens obliguen a replantejar-nos qüiestions més teòriques. Perquè, quina serà doncs, la jerarquia de significats en la concepció del temps de la societat moderna? ¿Està articulada en un cosmos sagrat, en un calendari explícit, amb aquest catàcter? $\dot{\chi}^{A}$ quin tipus de lògica respon aquesta articulació?

Aquestes preguntes, són les mateixes que demana també l'anàlisi del tet religiós. La jerarquia de significats en la concepció del temps és la que ve matcada per Ia racionalitat productiva tecnologica industrial i per les prioritats defirides per la societat de consum.

Sant Jaume i el dilluns de Pentecosta, s'inclinatia per aquest dartet, «puix no trenca Ia setmana laboral». Aquesta racionalitat productiva és en darrera instància la que is sustenta tota la seva proposta de calendari, ja que segons ell, «si és veritat que hi ha tradicions que són venerables -civils o religioses_, són encara més venerables les necessitats i la dinàmica dels temps presents». Corn que per a Llimona totes les festes s'haurien de trasiladar a dilluns, I'Onze de Setembre, el situaria al segon dilluns del mes (sic). Vista la seva proposta, la cristianització de les festes paganes va ser pluja menuda, i sens dubte, més respectuosa amb els costums del poble.

4. La supressió de la festa del Corpus, ja comentada anteriorment, va fer sorgir precisament aquest tipus d'argument tant en la defensa com en l'atac de la decisió. Mentre uns es referien a la historicitat de la festa i, per tant, la irrellevància de sotmetre-la a altres criteris - «acceptar la plena $\mathrm{i}$ exclusiva competencia del govern en la determinació de les f́estes, d'acord amb els criteris que democràticament s'estableixin en cada Iloc i en cada temps»-, i en canvi defensaven la seva «privatització» --eom a cristians, el sentit de la festa de Corpus el podem viure qualsevol dia de I'any i a l'hora que siguis- (diari Avui, Bústia, 22-X.1980, p. 4), d'altres sosterien precisament el contrati: «creiem que eliminat festes seculars del calendari és una arbitrarietat per part de la Generalitat», bo i denunciant I'ús de «procediments totalitatis tendents a la massificació de la gent i a la despersonalització dels pobles» $\mathrm{i}$ deI perill de «matar l'ànima collectiva» del país. (Diari Avui, a la mateixa secció Bústia del mateix dia 22-X-1980 que l'anterior carta.) 
Així mateix, en les reflexions inicials d'aquest article consideràvem les dificultats de mantenir un cosmos sagrat, una articulació de significats homogenis, coherents $\mathrm{i}$ amb un abast sobre la globalitat de la vida social. Al contrari, hi havia, sosteníem, una fragmentació calendària correlativa a la segmentació institucional, i una clara $\mathrm{i}$ radical pèrdua de significació d'aquests calendaris, que es reduien a mantenir un sentit pragmàtic, i per aquesta utilitat quedaven legitimats. La lògica de les poques articulacions significatives d'aquests calendaris especialitzats, de significació parcial, seria la imposada per la racionalitat tecnològica, i en definitiva, per la seva utilitat pràctica.

\section{Un calendari «invisible»?}

Però tal com passa amb les teories de la secularització, que acaben predient la desaparició del fenomen religiós, especialment pel seu caràcter eclesiocèntric - ja ens hi hem referit en repetides ocasions- (Estruch, 1972, 1977, 1980 i altres), també aquí pecaríem de miopia si acabéssim predicant la desaparició rasa del calendari a la societat moderna. De miopia $\mathrm{i}$ de ceguera, possiblement. Petquè tant els pressupòsits teòrics com la reflexió sobre la vida social moderna ens indiquen que el calendari, l'ordenament temporal social, segueix essent present i necessari. Mentte el calendari tradicional certament ha quedat força malparat en pocs anys i pei que en testa encata segueix sotmès a les pressions del procés de modernització, alhora també se'ns mostren, incipientment, les bases dels significats fonamentals, dels mites essencials del calendari modern. El cett és que no s'expressa, però, el calendari modern, d'una manera explícita, en un codi notmatiu clar, hi mantingut i transmès per una institució determinada amb uns especialistes reconeguts, ni, per tant, amb una articulació significativa explicita.

¿Podem parlar, potser, d'inespecializzació institucional del calendari modern? Ens sembla que no. La multiplicació mateixa de calendaris especialitzats, però, fa que no n'existeixi cap que explícitament es situi en un nivell superior, significativament parlant. I per tant, la proposta de calendari modern esdevé menys articulada, menys coherent, amb contradiccions, i molt més normativitzada en les seves múltiples àrees d'especialització, però amb una lògica signiffcativa molt menys elaborada.

Per tant, podriem dir que el calendari modern existeix, però no es veu. Cal parlar, doncs, de calendari invisible?

No citar aquí a T. Luckmann (1967) i a la seva obra La religión invi- 
sible seria inexcusable. Perquè la similitud dels punts d'artibada en la seva anàlisi de la religió $i$ en la nostra del calendari són obvis.

Es tracta d'un calendati invisible el de la societat moderna? Creiem que, pel que fa al caràcter normatiu del calendari, no es podria sostenir. Mai com ara, l'home s'havia refiat dels -i sotmès als- calendaris, les agendes, els rellotges...

En canvi, sí que aquest caràcter no visible, però existent, seria el que convindria al parlar dels significats del calendari modern.

L'aparició d'una esfera privada com a consequèencia de l'alta especialització institucional en l'esfera públicâ, és un fet. L'esfera pública esdevé fortament normativitzada, i en canvi, significativament dèbil. L'esfera privada permet mantenir una situació inversa: poc normativitzada $i$ amb una forta significativitat, essent el lloc de la creació dels significats últims. O si més no, de la illusió de l'absència de coetció pública i de la possibilitat d'autorealització personal.

Es en aquesta situació de privatització dels significats rellevants, últims, on trobem una explicació adequada al caràcter invisible del calendari modern.

El pas del calendari tradicional, festiu, al calendari modern, vacacional, ja ens anunciava aquest procés de privatització del calendari.

Atenció, però, a les observacions respecte a l'ús ideològic cel pluralisme i la privatització. En aquest cas, la privatització del calendari no significa la possibilitat de construir-se calendaris significativament rellevants al gust individual i privat. D'una banda, els calendaris normatius de les institucions públiques -empreses, escoles, burocràcies...- són els que en definitiva marquen els espais -els temps- de la vida privada, els seus límits i abast. I d'altra banda, els mecanismes de control i manipulació ideològica esdevenen més subtils, però sobretot molt més eficaços, quan s'han de dirigir a unitats privades, que en definitiva implica un alt grau d'aillament, de poca protecció i de permeabilitat.

Per posar un exemple, diréem que la participació en una festa religiosa tradicional - Corpus, Pasqua - podia tenir un caràcter coercitiu, certament, però en canvi no mantenia la illusió falsa de decisió personal i lliure que té qui, en la nostra societat, assisteix a un espectacle anunciat a la televisió.

5. Altres autors s'han referit, més explícitament, a la privatitzacio de la festa (H. Dougier, 1976, i A. Villadary, 1968). Però ens sembla incorrecte, o si més no, confús, ja que si bé el calendari és susceptible de privatització, en el sentit que utilitzem en el nostre trebail, en canvi la festa, igual que el mite, el titu i el símbol, no es poden sotmetre a la privatització sense perdre el que els caracteritza: «Ser un modeI per al món sences, un model per a l'eternitat...» (M. Eliade, 1957, p. 14.) 
La construcció privada de significats, en general, és precària, amb un equilibri inestable, situació en què bo $i$ donant-li una rellevància subjectiva tan gran, un petit trasbals, en canvi, esdevé dramàtic; però també és una situació que posa al descobert aquesta construcció i la sotmet a tota mena de pressions exteriors.

E1 refugi en la intimitat, contràriament a la illusió que proporcio na de llibertat individual i protecció, crea indefensió i submissió a la moda.

La privatització del calendari destrueix la festa. Ja ho hem dit, la festa es transforma progressivament en vacança. La festa és el temps ple, és la plenitud de l'bome (Brunner, 1963), la vacança és el temps buit, i probablement s'emparenta etimològicament amb evacuar. La vacança evacua la festa. Les vacances són l'antifesta (R. Caillois, 1950, p. 216); són el soistici de la vida privada, són el desig d'exhibir la inutilitat del propi temps (J. Baudrillard, 1970, pp. 243-250).

Els fenòmens del pluralisme i la privatització accentuen tant les diferències marginals sobre les quals es mantenen, que fan aparèixer com a invisibles els grans trets configuradors del calendari modern. Entre les múltiples decisions "privades» respecte al calendari, en la societat moderna hi ha una multiplicitat de diferències matginals, però també coincidèn. cies fonamentals de significats, latents, que nosaltres anomenariem mites moderns.

P. L. Berger (1973) considera tres posicions davant aquest estat produit pel procés de modernització: els qui l'accepten amb un «sí, però», els qui l'accepten sense reserves - la modernització com a redempció, com a esperança profunda i els qui s'hi oposen, veient en Ia modernització el camí cap a la desbumanització i la condemnació. T. Luckmann (1967), respecte la crisi de la religió tradicional, també menciona molt de passada tres sortides possibles, que nosaitres vam desenvolupar a Noves formes de religiositat: religió $i$ sexualitat (S. Cardús, 1976).

En primet lloc, hi hauria la possibilitat d'adoptat una actitud prereflexiva, temorenca, però que acabaria, generalment, sumant-se a la segona actitud, la més generalitzada, d'acceptació del sistema de valors modems seculars. En tetcer lloc, deia Luckmann, hi hauria una sortida possible en la readaptació del model oficial —de religió-, amb una parcial retirada del món, creant-se problemes ptàctics d'integració.

Una i altra tipologia ens semblen pròximes i interessants. Per nosaltres, la tercera sortida de Luckmann és la desmodernitzant de Berger. En el cas del calendari, estaria representada pels qui sense abandonar el calendari tradicional adaptarien aquest, en part, a les exigències del temps modern, amb un parcial aillament, en determinades ocasions, del món mo- 
dern. Els exemples serien nombrosos, però potser el més suggerent és el que ens relata J. M. Via Taltavull a La Vanguardia del 22-IV-1981, en un article titulat Entre lo religioso y lo vacacional. Comenta l'autor que alguns grups de cristians divideixen ara la tradicional Setmana Santa en dues parts certament diferenciades. En els primers dies - de dilluns a dimectes - després del treball, celebren els oficis corresponents al Dijous i Divendres Sant i la vigília pasqual. El Dijous Sant, en canvi, surten al camp, a disfrutar de les vacances de Setmana Santa. Diu Via Taltavuli: «Han complert amb la dimensió religiosa i creuen que compleixen també, sense haver de recordar ni atendre imposicions estrangeres, amb l'aspecte vacacional.» L'exemple parla per ell mateix. Sostenim que és el cas de l'actitud desmodernitzant, encara que no en un estat pur òbviament, perquè tampoc són corrents, en aquests grups, les actituds absolutament radicals de renúncia a certs avantatges de la societat moderna. Entre aquests grups hi ha d'haver, com diu Luckmann, problemes d'integració, que poden ser perfectament interpretats o racionalitzats pels grups afectats, com un cert «martiri» que sofririen per part de la modernització.

En una situació com la present, de crisi econòmica i d'un cert desencantament del progrés tècnic i la mateixa modernització, aquests grups tenen totes les possibilitats de veure engruixir els seus adeptes, més o menys convençuts, $\mathrm{i}$ amb més o menys incoherències, en les seves lluites teivindicatives de "recuperació» de festes tradicionals.

L'altre gran tipus d'opció, la de l'acceptació dels valors de la modernització, $i$, per tant, de les formes «invisibles» del calendari modern, serien els representants d'aquesta forma de «teencantament» de la societat actual, menys exòtica —ni gurus, ni sectes, ni ioga...-, però dominant, que és el de la creença en el progrés, la ciència, la tècnica, etc. És també el grup dels convençuts en el valor absolut del pluralisme i la privatització, com a fites importants en la liuita per la libertat i l'autonomia individual.

Creiem que convindria distingir, en aquests tipus, els individus o grups que tenen ptou capacitat per a la reconstrucció autònoma de significats, amb ełaboracions més travades $i$ per tant menys exposats als mecanismes de control de l'esfera privada, d'aquells altres individus - Ia majoria- que per manca de recursos culturals, econòmics, socials..., es veuen abocats a unes elaboracions dèbils, canviants, clarament exposats a la moda i a les coercions ideològiques i pràctiques de la publicitat, la televisió, etc.

El «bricolatge de significats» d'aquesta gran massa de gent es veu reduit: a la compra, en uns gtans magatzems, d'un «kit» amb totes les peces, tallades i preparades, amb un liibret precís d'instruccions de muntatge, $i$ que generalment surt tan costós com l'haver demanat ajuda a un especialista. Entre el «bricolatge de significats» d'aquests grups i l'antiga direcció 
espiritual, només hi ha la diferència de l'anonimat del libret d'instruccions del muntatge, davant la personalitat del director espiritual, i que és la que permet crear «l'illusori sentiment d'autonomia» (Luckmann, 1967, p. 108).

Pel que fa al grup d'èite, amb una certa capacitat pròpia de creació autònoma de significats, oscillaria entre les actituds d'escepticisme radical fins als qui s'adhereixen a moviments molt minoritaris que intenten conciliar ideologies i corrents de pensament diversos, sovint amb l'ajuda d'algun intellectual expert; i que el caràcter de grap petit, equip o moviment, protegeix una mica més de la precarietat de les construccions teòriques significatives.

Aplicat al calendari d'una manera concreta, hi trobariem exactament definits els dos grups: en l'elecció del tipus de vacances d'estiu, la gran massa decideix, individual $\mathfrak{i}$ autònomament, apilar-se en les platges més concorregudes de la costa. Alguns altres, pocs, saben escollir platges o paratges més inaccessibles, bé sigui per possibilitats econòmiques o bé per una més gran capacitat «d'exploració» de la geografia. Els primers "autònomament» hauran decidit triar una població «amb molt d'ambient», i els segons «autònomament» hauran decidit triar la tranquillitat, la solitud o la novetat d'un país desconegut.

Més en general, davant d'un període festiu determinat, per exemple Nadal, les decisions seran diverses: entre la típica construcció del pessebre, la missa del gall i l'àpat familiar i la novetat de les vacances en una multitudodinària estació d'esquí, entre la contestatàtia celebració d'una suposada «recuperació» del solstici d'hivern i unes vacances perduts dins una vall pirinenca en la intimitat familiar, les possibilitats són múltiples, i la combinació entre algunes d'elles no tan sols no és impossible malgrat la contradicció $i$ poca coherència que suposa, sino que potser és el més freqüent. En les actitudis modernitzants i desmodernitzants hi descobrim el caràcter ambivalent del sagrat: el respecte —a la religió de la modernitat- - i la transgressió - pel retorn a les relacions tradicionals o primitives de l'bome amb la natura, per la recuperació de solsticis i carnestoltes, etc.

$I$ en definitiva, les tipologies de Berger i Luckmann no representen grups totalment diferenciats, cadascun amb coherències internes pròpies, sinó més aviat són expressió de l'ambigüitat i l'ambivalència dels temps presents. Ambigüitat $i$ ambivalència, d'altra banda, que ens costa de pensar que no es trobi en tota societat i en tot individu. ${ }^{6}$

6. De fet, $Y$. Caro Baroja (1965) ja ens les documenta, aquestes ambigüitats, en el calendari tradicional, respecte al Carnaval i a les reaccions diverses i contradictòries que suscitava. 
La característica fonamental del temps modern no és únicament la seva proposta modernitzant, ni la desaparició total dels ritmes tradicionals. Més aviat sembla que aquell ritme passional del calendari tradicional entre Carnaval i Quaresma, Advent i Nadal, etc., en el calendari modern es tradueix en una oposició entre la Festa $i$ les Vacances, entre el temps ple i el temps buit, entre el temps viu $i$ el temps mort, entre viure'l plenament o haver de matar el temps.

No hi ha, doncs, calendari modern contra calendari tradicional, sinó calendari «invisible» que oposa un sagrat de respecte - progrés, tècnica, temps lliure - a un sagrat de transgressió - festa, sexe, revolució- en un nou procés de teencantament del món.

\section{Temps sagrat modem: de la festa a l'espectacle}

No seria del tot ximple, pensem, sintetitzar els canvis soferts en la significació i comprensió mođerna del calendari, afirmant que hem passat de l'era del Calendari del pagès a la Guia de l'oci.

El tepte que ens fa M. Eliade (1957, pp. 33-34) quan afirma que és precisament en l'anàlisi de l'actitud de l'home modern cara al temps on hom pot descobrir el camuflatge del seu comportament mitològic, és aquell al qual hem estat intentant de respondre parcialment al llarg d'aquest article.

La societat tradicional, en qualsevol gest o activitat, teproduia un model mític, des del treball a la festa, la guerra i la pau, els oficis i l'amor..., tot es podia referir a un temps primordial, a un gest creador. Però, segons Eliade, la caiguda en el temps comença amb el fet de la dessacralizzació del treball.

Hem vist com l'home modern «mata el temps treballant, i s'esforça per sortir-ne en el lleure» (M. Eliade, 1957, p. 37). L'historiador de les religions creu que aquesta caiguda en el temps suposa una pèrdua camuflada de la Hibertat, i que l'única evasió possible a escala collectiva és la distracció, la diversió, l'espectacle. Per camins diferents s'arriba a plantejaments semblants: comportament mitic camuflat - calendari invisible; restricció del camp d'acció del mite en el món modern i pèrdua deł domini global en tots els sectors de la vida - significació parcial del calendari com a cosmos sagrat; repressió del mite i localització en zones secundàries de la societat - rellevància subjectiva del calendari i privatització dels sistemes de significats: hom està afirmant el mateix.

El calendari, invisible de significats, perd els grans punts de referència festius anuals, però troba els seus punts de rellevància en els espectacles. 
En els espectacles —i per alguns en la lectura- hom retroba el temps concentrat, intens, proper $o$ idèntic al temps màgic i religiós.?

En els espectacles es reprodueix una tensió entre el sagrat de tespecte i el de transgressió: espectacles d'adoració a la ciència, el progrés i l'ordre, i espectacles sacrílegs de transgressió. Si agaféssim una Guia de l'oci, una cartellera d'espectacles de qualsevol diari, l'impressió d'ambivalència de l'espectacle és fulminant. Pres un dia a l'atzar, mentre redactàvem aquest treball, el diari anunciava dos films, costat per costat: Sobresalientes en erotismo, anunciat com a model de desvergonyiment, i Sissí, en una reposició per fruir de «la joventut la bellesa i la felicitat». Vet aquí els grans periodes passionals, el Carnaval i la Quaresma, reduïts a fets pun. tuals, quotidians, d'elecció i fruïció privada. Sempre - suposem- uns han preferit celebrar el Carnaval i d'altres la Quaresma com uns seleccionen un film i els altres l'altre...

L'interessant d'observar és que l'ambivalència del sagrat és viscuda en les representacions que en proporciona l'espectacle. La transgressió es produeix per l'identificació amb el protagonista, petò el respecte també està mediatitzat per una escenificació. El Carnaval i la Quaresma també eten en el fons transgressions i respectes tepresentats. 'La diferència rau sobretot en el grau d'implicació - de "participació", es diu en els espec. tacles-: per exemple, la transgressió de l'ordre establert per l'assistència a un recital de cançó d'en Raimon a finals dels anys seixanta, era viscuda simbòlicament en les cançons, però confirmada amb contundència per les prohibicions governatives i les corredisses habituals a la sortida de l'espectacle. Ata bé, l'espectacle corrent actual es caracteritza més aviat per una actitud passiva, per l'elecció privada i individual, per l'accés immediat i també el caràcter fugisser de les seves propostes.

Es fonamental insistir en aquesta transformació en espectacle de tota experiència rellevant en la que sembla obsessionada la nostra societat. La conversió de l'assaltament al Congtés de Diputats espanyol per la guàrdia civil en un espectacle televisiu repetit diriem gairebé abusivament; l'eslògan de certa premsa que diu «nosaltres hi érem presents» amb la imatge corresponent; la possibilitat d'assistir com a espectadors a l'assalt al Banc Central de Barcelona des d'una còmoda butaca i en directe; la impressió que la notícia de l'atemptat a Joan Pau II quedava incompleta per l'absència d'imatges en els primers teportatges informatius, etc., ens con. 5

7. H. Cox fa extensible aquesta consideració als medis de comunicació: «Per la meva part, crec que caldria sobretot considerar eils mass media com a formes disfressades de religión $(1973$, p. 13). 
firmen amb dades properes aquesta voluntat o necessitat de convertir en espectacie tota possible transgressió a l'ordre social.

I possiblement, la dartera «transgressió» que arribarà en forma d'espectacle quotidià, banalitzant-la fins a les darreres conseqüències, a través de l'aparell de televisió, serà la del sexe i la de la mort. En paraules de J. L. Atanguren (1981), "aquest "veure morir" es pot degradar, tornar-se morbós i banal espectacle, ara en minúscula (la "mort en directe", el televisiu Death watch)». I el mateix pot succeir en el sexe, com ja passa en d'altres paisos. Però per què aquest relatiu retard en la televisió respecte d'altres medis? Perquè la televisió accentua encara més, fins a l'extrem, aquella immediatesa en l'accedit-hi, la indefensió de l'espectador no avisat del que hi passarà, i la fugacitat de la imatge i la seva poca o nulla empremta en la memòria, que radicalitzarà el ptocés de banalització de l'experiència tepresentada.

És en aquest sentit que podem parlar de la restricció del camp d'acció dels mites, de la repressió del mite per la seva localització en zones secundàries - privades, etc.

El calendati modern, en lloc de permetre'ns una «passejada pel temps» en forma de celebracions festives, repeticions rituals, rememoracions mín tiques, ens porta a «fugir del temps» per la banalització de tota experiència passada o projecte futur, concentrant tota la seva força en el moment present. I així, el passat es converteix en aventures «de pellícula» i el futur en ciència-ficció. ${ }^{8}$

Algunes, poques, festes encara marquen punts d'exaltació collectiva. Segons uns, cada vegada menys. Segons altres, serien en vies de recuperació. Però ja són festes-espectacle. B. Besret (1971) compara la festa de Pasqua dels cristians amb el que Woodstock ha sigut per una generació de «hippies». Però els Woodstock també s'han acabat: festes o festivals que eren, per $B$. Bestet, la realització utòpica del regne en què cadascú s'entregava fins a fondre's entre tots.

La festa només pot sorgir allà on és esperada, desitjada, llargament preparada, diu Besret. És per això que els pobles més pobres són els qui, en el nostre món, han guardat el sentit més viu de la festa. L'espera, el desig, la llarga preparació són el contrari de la televisió i el vídeo. La festa

8. Respecte a la ficcio, afirma M. Maffesoli (1979): “Viure l'instant, viure'l plenament sense preocupar-se de l'esdevenidor, és allà on allò que és fantàstic retroba el mite que recapitula en la simultaneïtat el que cispersa en el temps lineal. En aquest sentit, la ficció és "el doble" de la vida quotidiana, en el sentit més fort del terme, el que tants pensadors han subratliat $\mathrm{i}$ que assenyala amb força el desig d'eternitat» (p. 82). 
es torna festival, es rutinitza, es torna pràctica, i esdevé finaiment espectacle passiu.

A Godspell, Ctist es transforma també en un clown, un arlequí. $\mathrm{H}$. Cox (1979, p. 166) veu en aquesta disfressa la personificacio de la festa i la fantasia en un temps, diu, que les ha perdut gairebé totes dues.

L'home modern busca en l'espectacle aqquesta reduida possibilitat d'experiència mítica, «necessitat consubstancial a la condició bumana d'expressar l'angoixa davant el Temps» (Eliade 1957, p. 39).

Sembla clar, però, que l'espectacle no és suficient com a canal d'expressió d'aquesta angoixa. Sembla que el comportament mitològic no es resigna a uns canals estrets, a la immediatesá temporal i a la mediatització de la tècnica. El pluralisme, la privatització, no suposen inconvenients pràctics en el funcionament correcte de les institucions socials. Petò deixen coixos, mal resolts, els mecanismes de construcció de significats últims, d'expressió mítica i ritual.

En la cultura juvenil es constata aquesta insatisfacció. S'hi repeteix la collisió entre les estructures temporals modernes, que no els satisfan, i les pre-modernes, segons Berger (1973, p. 196), o potser millor dit encara, les postmodernes. "A aquests grups de joves, el que els importa no és l'adaptació a la modernitat, sinó, al contrari, l'expressió d'una dissidència radical respecte d'ella: tan radical que ni tan sols es proposen la lluita activa en contra d'ella», diu J. L. Aranguren (1975, p. 44).

Aquesta dissidència, proclamant $\mathrm{i}$ exigint un «ara!», no planificador ni disposat a l'espera, podria ser una manifestació de la insatisfacció d'un calendari modern desproporcionat entre una gran coercivitat normativa i una precària possibilitat de construccions de significats. L'«ara!» dels joves és una altra fugida del Temps i la seva angoixa.

Ens sembla interessant preguntar-nos, a partir dels estudis de J. Piaget sobre l'evolució de la noció de temps en el nen, si h'home de la societat moderna no estatà patint, tespecte el temps, un procés d'infantilització. Segons Piaget (1946), «el que és propi del pensament en els seus inicis és, en efecte, el considerar com a absolutes les perspectives momentànies en les que està compromès, $i$, per consegüent, el no "agrupar-les" segons els lligams de relacions recíproques. Aquest realisme inicial és, alhora, una forma d'egocentrisme, ja que porta a situar l'estat de consciència actualment viscuda al centre de tot, $i$ un factor d'irreversibilitat, ja que així l'immediat succeeix a l'immediat sense construcció de conjunt. Més precisament, egocentrisme i irreversibilitat són una sola i mateixa cosa. (...) En el domini del temps psicologic, una tal actitud condueix a viure només el present $i$ a no conèixer el passat si no és pels seus resultats: d'aqui, les dificultats de "reflexió" (en el sentit propi del terme), que hem anotat, $i$ la doble inca- 
pacitat de reconstruir un ordre de successió i d'encaixar les durades segons un sistema d'estimacions coherents» (p. 275, el subratllat és nostre).

La similitud d'aquestes reflexions amb la descripció que feia M. Eliade de la concepció del temps en les civilitzacions primitives - desvalorització del temps, present atemporal, intenció antihistòrica, no valoració de la memòria... (1951, pp. 40, 81, 86) - i, d'altra banda, amb el que anomenàvem «l'ara!» juvenil, ens semblen evidents.

Sovint, els corrents de cultura juvenil prenen formes ecologistes. I llavors, el mite de Progrés, ànima de la civilització industrial, religió secular $\rightarrow$ diu D. Léger, 1980 (p. 13) tr és substituit per l'apocalipsi que ens prediu que els temps són pròxims. La percepció apocalíptica del món modern va acompanyada per unes darreres crides a la conversió: la salvació està en el retorn a la natura i el seu ordre: «Allà, tot és ordre $i$ bellesa...» La necessitat de supervivència d'aquests grups opera una recodificació religiosa de l'experiència ecològica. Alguns autors relacionen aquesta recerca de noves formes socials amb la proximitat de la fi del segon milleni: «Una qüestió difícil de saber és en quina mesura l'angoixa de la fi del milleni pot jugar al nivell, sovint suspecte, de "P'inconscient collectiu", un paper accelerador o àdhuc provocador de les catàstrofes anunciades» (A. C. Découflé, 1975, p. 37).

En un altre nivell, l'èxit de masses actual de la ciència-ficció $i$ del catastrofisme, especialment en ei cinema i els còmics, és vist per L. V. Thomas com la localització dels «fantasmes de regressió i de fugida, fantasmes de defensa contra la mort, que són part integrant de la consciència humana, però que prenen, en un món d'inseguretats, una profunditat $i$ una acuïtat crescudes» (citat a D. Léger, 1980, p. 15).

El cinema de ciència-ficció actual, com a cinema que atrau un extraordinari nombre d'espectadors, convertint-se en un sector punta de la in. dústria cinematogràfica, s'origina l'any 1968, amb una pellícula de Stanley Kubrick anomenada 2001. Una odissea en l'espai. La característica foriamental -i diferencial- és el fonament metafísic del relat. Després l'han seguit, amb èxits aclaparadors, pellícules com La guerra de les gatàxies (1976) i d'altres. Per en F. Fanes (1980) aquests films entren en el laberint de la metafísica. «Si les pellícules - diu l'autor- són com mirails en els quals llueixen els desigs $\mathrm{i}$ somnis del públic, ¿què reflecteix ara el mirail màgic a través del qual es manifesten tots aquests anhels més o menys metafòrics?» I ell mateix respon: «La humanitat dutant el segle actual s'havia convertit en adoradora d'un nou déu -el progrés- del qual la ciència era el seu profeta. En el darrer terç del segle, aquest déu i el seu profeta han passat de generar la més gran de les esperances, a elaborar el més tenebrós dels 
horrors: el futur com a incertesa.» D'aquí que F. Fanes considera la ciènciaficció com la resposta a un desig present de metafísica.

Totes aquestes reflexions semblen insistir en la impressió que el calendari modern, l'estructuració temporal actual, però potser en general les formes noves de religiositat emergent, esdevenen insuficients.

Què volem dir que són insuficients? Doncs que no tesponen d'una manera efectiva a les necessitats de donació i construcció de sentits, especialment de significats últims.

El calendari modern suprimeix la festa i es refugia en l'espectacle, en les vacances: en la tepresentació $i$ en el temps buit. És llavors quan el domini significatiu del temps, qualitat específicament humara i social, és precari $\mathrm{i}$ esdevé angoixa davant el temps.

Aquesta és la convicció d'autors com Duvignaud (1977, p. 77) que veuen possible que la festa bagi estat reemplaçada pel somni $i$ la follia. $O$ de F. Caradec, que creu que la desaparició de les festes comporta l'aparició d'activitats agressives compensadores d'aquesta frustració, i que aques. ta substitució de la festa per la vacança comporta una manera de viure desesperada «caicada en l'angoixa de la mort», pel «gran repòs», en lloc d'equilibrar aquesta angoixa amb els tenaixements de la festa primitiva (1977, pp. 20 i 138). I també R. Caillois, quan es pregunta on es pot alliberar els instints de l'individu reprimits per les necessitats de l'existència organitzada, davant l'absència de festes. Opina que -recordem-hol'antiga alternança de la festa i el treball, de l'èxtasi i el domini, es troba teemplaçada per una altra alternança, d'ordre diferent però amb un volum corresponent a la primera: la de la pau i la guerra, la de la prosperitat i Ia destrucció dels resultats d'aquesta prosperitat, la de la tranquillitat regulada i de la violència obligatòria: guerra, destrucció i violència...

Per H. Cox, el lligam entre el declinar de la festa i la mort de Déu es pot demostrat plenament, i el preu pagat per la modernitat per l'home occidental, és la pèrdua de la seva ànima, per l'empobriment dels seus elements vitals: el sentit de la festa i la fantasia (Cox, 1969, pp. 17 i 39). I encara, M. Eliade (1963, p. 88), en l'art contemporani, hi veu una clara revalorització del mite de la fi del món.

Però la constatació més interessant en tots aquests autors $\mathrm{i}$ aquestes reflexions que fins ara hem anat comentant, és la coincidència unànime en un aspecte: la proximitat ternàtica de la crisi de la festa amb la discussió sobre el sentit de la mort. Hem vist com l'angoixa davant el temps s'expressa en la nostra societat en referència gairebé exclusiva a la mort: Matem el temps, en fugim. Els nous apocalíptics, els millenarismes, la ciència-ficció i el catastrofisme, tots ells com a fantasmes de defensa contra la mort. La proximitat de l'art contempotani amb la fi del món i les va. 
«Papers»: Revista de Sociologia

cances com a temps calcat en l'angoixa de la mort. La festa substituida per la guerra, la destrucció i la violència. I la pèrdua de l'ànima per la pèrdua de la festa.

Al costat d'aquesta visió més pessimista sobre el present del calendari modern, bé cal fer palès una renovada voluntat actuai de retrobar la festa. En aquesta obsessió (Autrement, núm. 7) per a la recuperació de la festa, hi ha d'haver, necessàriament, un desig d'exorcitzar la mort de la collectivitat, de transgredir, per la festa, el temps lliure, les vacances i l'espectacle passiu; un desig més o menys conscient de reconstruir una experiència temporal i un calendari plenament reencantats. 


\section{BIBLIOGRAFIA CITADA}

Aranguren, J. L. (1975): «Changements culturels de la Jeunesse à l'égard de la Religion» a Actes de la $13 e$. Conference International de Sociola gie Religieuse, Lloret de Mar, pp. 9-26.

- (1975): Talante, juventud y moral. Madrid, Ediciones Paulinas.

- (1981): «Sobre cultura y moral de la muerte y del sucidio», El Pais, 14.V-1981, p. 15.

Baudrillard, Jean (1970): La société de consommation. París, Gallimard.

Berger, Peter i Luckmann, Thomas (1966): The Social Construction of Reality, Nova York, Doubleday. Edició castellana, La construcción social de la realidad, Buenos Aires, Amorrortu, 2a. ed. 1972.

Berger, Peter L., Berger, Brigitte i Keliner, Hansfried (1973): The Homeless Mind. Modernization and Consciousness. Nova York, Random House. Edició castellana, Un mundo sin hogar (Modernización y Conciencia). Santander, Sal Terrae, 1979.

BesRE'T, Bernard (1971): Clefs pour une Nouvelle Église. París, Ed. Se ghers.

BleEker, C. J. i Widengren, G. (1969): Historia Religionum. Handbook for the History of Religions. J. Brill, Leiden, Holanda, Edició castella. na: Historia Religionum. Manual de bistoria de las religiones. Madrid, Ediciones Cristiandad, 1973. 2 vol.

Brunner, August (1955): Die Religion, Friburg, Herder. Edició castellana, La Religión, Barcelona, Herder, 1963.

CaIl Lors, Roger (1950): L'bomme et le sacré. París, Gallimard.

CARADEC, François (1977): La farce et le sacré. Fêtes et farceurs, mythes et mystificateurs. París, Casterman.

CARdús, Salvador (1976): Noves formes de religiositat: Religió $i$ Sexualitat. Universitat Autònoma de Barcelona.

Caro Baroja, Julio (1965): El Carnaval. Madrid, Taurus.

- (1979): La estación de amor. Fiestas populares de mayo a San Juan. Madrid, Taurus.

Cox, Harvey (1969): The Fieast of Fools, Harvard University Press. Edició citada, La fête des fous, París, Seunì, 1971. 
«Papers»: Revista de Sociologia

- (1973): The Seduction of the Spirit, Nova York, Simon and Shuster. Edició citada, La séduction de l'esprit, París, Seuil, 1976.

Danielou, J. i Marrou, H. (1963): Nouvelle bistoire de l'Église. Vol. I, París, Seuil, 1963.

Decouflé, André-Clément (1975): «Un aspect de la temporalité du sacré: L'an 2000 et la résurgence du thème de la fin du monde et recommencement des temps». Cabiers Int. Symbolisme, núm. 27-28, pp. 33-39.

DOUgIER, Henry (1976): «L'exorcisme». Autrement 7, La fête, cette bantise, pp. 3-7.

Duvignaud, Jean (1977): Le don du rien. París, Ed. Stock.

EliAde, Mircea (1951): Le mythe de l'éternel retour. Acbétypes et répétition. París, Gallimard. Edició castellana, El mito del eterno retorno. Madrid, Alianza Editorial, 1972.

- (1957): Mytbes, rêves et mystères, París, Gallimard.

- (1957): Das Heilige und das Profane, Rowohits Deutsche Enzyklopädie. Edició castellana, Lo Sagrado y lo profano, Madrid, Ed. Guadarra$\mathrm{ma}, 1967$.

- (1963): Aspects du mythe. París, Gallimard. Edició castellana, Mito y realidad, Madrid, Guadarrama, 2a. ed. 1973.

EsTRUCH, Joan (1972): La innovación religiosa, Barcelona, Ariel.

- (1980): «El mite de la secularització». Ponència presentada a les Jornades de Filosofia de la Religió, organitzades per la Universitat Autònoma de Barcelona, febrer de 1980.

Fanes, Fèlix (1980): «La ciencia-ficción como metafísica», La Vanguardia, 20-XII-1980, p. 41.

Febvre, L. (1942): Le problème de l'incroyance au 16e. siècle. París, Albin Michel. Ed. citada, 1975.

LEGER, Danièle (1980): «Les nouveaux apocalyptiques», Lumière et Vie 148/29 pp. 13-31.

LiIMona, Jordi (1979): «Unes propostes de calendari» Avui, 4-XII, p. 3. Lucrmann, Thomas (1967): The invisible Religion. London, Collier/ Macmillan. Edició castellana, La religión invisible, Salamanca, Ed. Sígueme, 1973.

Maffesoli, Michel (1979): La conquête du présent. Paris, PUF.

PIAGE'T, Jean (1946): Le développement de la notion de temps chez l'enfant. París, PUF. 2a. edició citada, 1973.

VAN DER LEEUW, G. (1948): Edició francesa, La Religion dans son essence et ses manifestations. París, Payot.

Via Taltavull, J. M. (1981): «Entre lo religioso y lo vacacional», La Vanguardia, 22-IV-1981.

Villadary, Agnès (1968): Fête et vie quolidienne. París, Les Editions Ouvrières. 